\title{
Consequences of Fiscal Adjustment and Public Finance Management. The Costs of Limiting the Fiscal Imbalance in Eurozone Countries.
}

\begin{abstract}
This article focuses on the effects of corrections to the budgetary policy in eurozone economies. The goal of the text is to check if advancement in implementing modern tools of public management is helpful in the time of fiscal adjustment. We assume that the most important role of a performance approach in conducting fiscal policy is the ability of government to implement active policy meant as structural changes in the composition of public expenditures. In the case of the need to cut general levels of public spending, public sector managers who have knowledge of performance effects of public policies should be able to conduct fiscal adjustment in such a way as to minimise negative outcomes of spending correction on society. The structure of the text is as follows. First, we present some insights on the economic effects of fiscal adjustment. Then, we discuss the concept of performance management presented in the theory and policy agendas of international institutions such as the European Union or the OECD (Organization for Economic Cooperation and Development). Finally, we present the result of an empirical exercise that is designed to combine the level of advancement in implementing performance budgeting (PB) and the social cost of fiscal adjustment in eurozone economies. The most important finding of the research is that PB tools seem to have very limited usefulness in a time of fiscal adjustment. There is no statistical evidence that countries advanced in utilisation of PB tools conduct more active fiscal policy - approach of cutting all expenditures across the border by given percentage rather than looking at priorities and social outcomes of fiscal adjustment dominates in all cases.
\end{abstract}

KEYWORDS: public finance, fiscal adjustment, efficiency

JET: H30, H61, H72

RECEIVED 11 December 2017; ACCEPTED 23 January 2019.

\section{INTRODUCTION}

Fiscal adjustment, defined as limiting the level of fiscal deficit, represents a major correction in fiscal policy and, consequently, it cannot have zero impact on the state of the economy. A change in the principal fiscal parameters (public sector balance, public debt dynamics, level of public revenues and spending) may be the outcome of either discretionary activities or the operation of the so-called automatic stabilisers, which should spontaneously adjust the fiscal balance to the business cycle. Typical fiscal balance indicators, such as public balance and public debt-to-GDP (Gross Domestic Product) ratios, fail to give a reliable picture of changes implemented in the public policy, as they are strongly dependent both on the fluctuation of the nominal and real GDP and on the amount of interest payments, which are usually beyond the control of those in power. From this point of view, it seems appropriate to use the indicator suggested by Alesina, Perotti and Tavares (1998), which is the change in the primary budget balance. This has a self-evident advantage of excluding the impact of costs of debt servicing on the budget balance. As we are mostly interested here in public spending management models, another fiscal policy adjustment indicator that we will use is the dynamics and structure of public spending, enabling us to assess whether the instruments for managing public expenditure have an impact on the social effects of public sector reforms.

1 Head of Department of Financial Management in Organisation, University of Warsaw, Faculty of Management. Email: www.postula.eu 
In the typical Keynesian model of economy, fiscal adjustment should, at least in the short term, have recessionary effects, because both reduced public spending and increased taxes decrease the current flow of aggregate demand, which must affect the economic dynamism (Nuti, 2014). However, there are considerable concerns that a simple aggregate demand model should be adapted to the current circumstances in which present-day governments operate. Tanzi (2012) claimed that the current state of public finance (high public debt) and the demographic situation have a major impact on economic entities' behaviours, mainly through the effect of household expectations of future taxes. Also, the crisis of 2008 was not a typical recession resulting from aggregate demand fluctuations in the business cycle, but it had clearly structural reasons. This is why expansive fiscal policy is not very effective and fiscal adjustment does not involve high costs defined as decreased GDP dynamics.

Quantitative research (Alesina, Perotti \& Tavares, 1998; Perotti, 2011; IMF, 2012, 2013) indicates that it is possible to demonstrate examples of pro-growth fiscal adjustment; thus, decreasing fiscal imbalance can lead to economic recovery. As the decrease in the scale of fiscal imbalance is very long lasting, after several years, there is no deterioration in the debt and deficit indicators, as long as the adjustment mostly involves the spending side, rather than raising taxes, as the increase in public revenues is usually temporary in nature. Another important thing is the structure of spending - what needs to be reduced is current expenses, mainly transfers and wages in the public sector, rather than public investment, where the highest spending multipliers are recorded.

There has been a marked increase in the interest in the effects of structural changes in the fiscal policy, which should come as no surprise, as most highly developed countries must make an effort to reduce fiscal imbalance. The deficit and public debt levels were relatively high in many countries even before the financial crisis of 2008 broke out. The need to mitigate the costs of the crisis (the functioning of automatic stabilisers and discretionary measures, such as bailout of the financial sector) greatly increased the scale of public debt, even where budgetary surpluses were recorded before the crisis, which was the case in both Spain and Ireland. Contrary to commonly held opinions, the need to reduce budgetary imbalance is not mainly imposed by the cost of financing the public debt. Dell'Erba, Mattina and Roitman (2013) estimated that only about One-third of the cases of fiscal adjustment undertaken were enforced by financial markets either refusing to finance a debt or imposing such high costs of finance that governments were forced to significantly reduce their borrowing needs. Therefore, as a rule, reducing the scale of imbalance of public finance was either a conscious decision of respective countries that are obliged to meet relevant debt and deficit levels, as in the European Union, or a way to address the demand of societies (taxpayers) who realise the negative consequences of public debt.

The aforementioned quantitative research into the effects of fiscal adjustment is limited to the analysis of macroeconomic parameters - how GDP dynamics is affected by given size of fiscal adjustment. Inevitably, the empirical material relies only to a limited degree on the experience of the recent years and, consequently, it does not account for the specifics of eurozone member states. Perotti (2011), in the analysed cases of expansive fiscal adjustment, showed the cases of Denmark and Ireland in the 1980s, as well as those of Finland and Sweden in early 1990s. In all the cases indicated, the positive response of GDP dynamics to limiting the budget deficit was, to a great extent, a result of a change in macroeconomic policy parameters. Each of these countries had its own currency at the time, so fiscal policy tightening could go hand in hand with the loosening of monetary parameters; the central bank's interest rates fell, and the exchange rate weakened. Such changes in the monetary policy are not possible in eurozone countries, which is why these economies are good research material for assessing the effects of corrections in fiscal policy. It can be pointed out that despite a single level of the central bank's interest rate being in place across all of the eurozone, the cost of capital in different member states is not the same, which is reflected, for example, by the different yield of respective governments' treasury bonds. The situation is similar for the exchange rate - nominal changes to the exchange rate in monetary union member states are impossible by definition, but there may be fluctuations of the real rate, which stems from differences in the inflation rate between various countries. However, these circumstances do not change the fact that fiscal policy is the only area of macroeconomic policy left in the control of eurozone member state authorities, which makes it much easier to analyse quantitative relationships; the economic impact of running a given fiscal policy depends nearly exclusively on fiscal parameters (debt, balance, public spending dynamics and structure) and on the quality of the public finance system, which is a mechanism for translating political decisions into the state of economy and society.

The goal of our study is to evaluate the extent to which the advanced implementation of performance budgeting $(\mathrm{PB})$ instruments contributes to conscious public finance management, that is, achieving the assumed social and economic effects at given levels of public spending. Usually, the effects of public spending are assessed in the period during which expenditure is increased, for example, when either implementing a given project or increasing its scale. PB instruments should be a useful tool also in a period when, for various reasons, spending must be curbed. We assume that countries that are advanced in using quantitative assessments of public policy effects should be quite familiar with the effects of different spending levels on the condition of respective areas. Fiscal 
adjustment defined as fiscal deficit reduction should have, in such countries, relatively low social costs, as those in power, having access to detailed data on the effects of public spending, should limit it in such a structure to minimise the negative impact of the reduced expenditure on the society. We should verify, in quantitative terms, the following hypotheses:

- In countries that are highly advanced in implementing PB, the spending adjustment (reduction) should be largely discretionary (different scope of cuts in respective areas), rather than purely statistical, with all spending categories reduced by a given amount;

- In economies where the public finance system is based, to a greater extent, on the PB principles, reducing imbalance and public spending should have lesser negative effects for society than in countries that use PB instruments to a lesser extent.

The metrics of negative effects will include GDP dynamics, changes in the poverty rate and income stratification. We assume that the above metrics are clearly of interest to those in power, so they should run a policy that leads to the lesser possible deterioration of such metrics. Hence, the question is whether the use of $\mathrm{PB}$ instruments indeed provides instruments for running a specific discretionary public finance management policy or is, instead, limited to the public finance sector's presentation issues.

The level of advancement of PB implementation is identified based on a survey conducted by the OECD (2015). Respective countries are evaluated by indicating whether instruments from respective areas are used in public finance management:

- General guidelines and definitions for the PB process,

- Standard template(s) for reporting performance information back to the Central Budgetary Authorities (CBA),

- Standard performance rating system,

- Standard set of performance indicators and/or targets,

- Standard ICT (Information and Communication Technologies) tool/application for entering and reporting performance information to the CBA.

Affirmative/negative answers help classify countries on the scale from 0 (either instruments are not used in any area or a given country does not use any of the principles of $\mathrm{PB}$ ) to 5, where all the principles of using $\mathrm{PB}$ are applied in the practice of public finance management.

\section{Transparency and principles of public finance management}

The quality and transparency of the public finance system are undoubtedly of significance to the assessment of the actual situation of state finance and of the shape of fiscal policy. The scale of complexity of public systems and ambiguities in the rules of macroeconomic statistics make the analysis difficult. This can be seen, first and foremost, in the discrepancies between data relating to the budget balance and to its impact on the level of public debt, which should be strictly correlated. This is not a rule, however, as there is a whole range of possible ways to classify transactions where the level of public debt is not directly related to the current budget balance, and vice versa. Such discrepancies make it very difficult for domestic (taxpayers, beneficiaries of public goods) and foreign entities, such as international organisations or buyers of securities, to assess a given government's fiscal policy. Comparative studies (Weber, 2012) confirm that countries with the highest transparency of public finance record the lowest discrepancies in the data describing the state of public finance, that is, the level of debt directly follows from the budget balance (EC, 2015, p. 23). Hence, one can see that transparency of public finance has a fundamental impact on the reliability of research into the effects of fiscal policy, as it safeguards the reliability of principal figures that describe the state of public finance.

In the literature, there is considerable confusion about the use of the term $P B$ - there is no consensus either as to the definition of the term itself or as to the major goals of using PB techniques. Public management inevitably combines elements of several social sciences, such as economics, finance, management, political science or social psychology and sociology, which is why representatives of various sciences whose area of study includes the functioning of the public sector have different approaches as to how to assess the functioning of the public sector. It seems that the simplest definition of PB is presented by the OECD (OECD, 2003, p. 7), where it is defined as 'budgeting that links the funds allocated to measurable results'. Such a definition is self-evident, at first glance, but 'budgeting' can be interpreted as different things, for example, as creating a budget (defining the allocation of funds to respective 
purposes/institutions/areas), as presentation or, last but not least, as an assessment/evaluation of the way public funds are spent. The objectives of introducing new methods of public finance management are also varied, as they can include improved allocation of resources (distribution of funds between different areas and institutions), efficient and effective functioning of respective institutions and greater transparency of the public finance system, which is meant to enable objective assessment of public policies. Robinson and Brumby (2005) pointed out that the aforementioned theoretical questions, combined with the known problems with measuring the effects of public policies, ${ }^{3}$ make it very difficult to clearly establish whether PB is an effective method of managing the public sector. Utz (2010), in his study combining theoretical discussion and insights from interviews with Swiss public managers, showed that the most important channel of increasing efficiency should be a higher scale of independence of managers, which goes with changing the model from an input-based to an outcomes-based one.

According to the OECD surveys, the results of which were published in 2007, 2011 and 2016, nearly all the OECD countries, that is, 29 of 33 countries surveyed, declare that when analysing the level of public spending (programme) implementation, they use information on products (i.e. quantity, quality, value of goods and public services) and on the results defined as the impact on social and economic indicators. In addition, it follows from the surveys that 24 countries use synthetic measures for products and results and in 12 countries, other forms of information on non-financial effects of the public tasks executed are presented. What is of much greater importance, however, is the issue of how the efficiency information is used by public administration. The data collected indicate a limited use of such information. For 19 countries, efficiency information is used to provide a rationale for the existing allocation of funds. Meanwhile, efficiency information is used in 18 countries to set goals and to manage programmes, and 15 countries indicated its utility in reviewing plans and programmes. The results of the OECD surveys indicate that a direct impact of efficiency data on the allocation of public spending is declared in the minority of the 33 OECD countries surveyed. When asked about the consequences of using efficiency information, the ability to make changes within programmes is indicated in 12 cases, changes in allocations between programmes are indicated in 10 countries and only 9 countries reported that the effects achieved contributed to limiting the spending.

The experience of the OECD countries also indicates discrepancies between the object of measurement and what can be managed in practical terms. According to the information acquired from an OECD review, another major problem is the adequate response to efficiency being insufficient compared to the one planned. Depending on the structure of tasks used by a given national administration, the capabilities for measuring the results of tasks and the accuracy of that measurement may vary. Oftentimes, despite years of experience, the final results for some diverse public tasks are hard to either pinpoint or quantify.

The cited outcomes of the OECD review allow the opinion that, admittedly, the efficiency assessment is used in managing public programmes, but it does not represent a decisive criterion in decisions on public funds' allocation. On the other hand, however, data from the OECD review indicate that the efficiency information has quite an important place in public management, which is often denied in discussions. Indeed, decisions on public funds' allocation are, eventually, made based on a set of criteria including efficiency data, if available. Lack of this information greatly lowers the quality of public management processes (Kelly and Rubin, 2005, p.584).

The surveys conducted by the OECD reveal that governments are more and more likely to include efficiency information in the materials they present. One of the goals of such measures is to 'promote' administrators who achieve better efficiency results, whilst also aiming to increase the transparency of public spending. In the OECD member countries, there are major differences in the approach, with no consensus on the optimum management by objectives system to be used. This is the case even though, the OECD, in its papers, assesses the task-based budgeting system in several categories. Unfortunately, the results of surveys give direct arguments for the theory that most OECD member countries present efficiency information whilst rarely using it in the allocation of funds.

When analysing the OECD surveys, it is difficult to spot any direct measures taken by countries to increase the importance of management by objectives in the process of allocating public funds and ensuring accountability for the implementation of public tasks. When it comes to the EU member states, this direction was to be expected, not only because of the growing awareness of the need for fiscal consolidation but also because of the fact that relevant regulations had been introduced at the EU level. Indeed, the

3 The biggest problem is the issue of measuring the effect of public policies. Whilst it is possible to identify, with relative precision, the quantitative products and results of public institutions' activities, the effect, or the desirable change in a given domain, is very hard to measure unambiguously and, at the same time, there are objective doubts as to whether the change observed is the result of public sector activity or whether other factors, largely independent of the state, play a more important role. Another problem analysed by Eisenkopf (2009) is the agency problem - the choice of indicators is biased by public managers who are willing to show the efficiency of their institution. 
Council Directive on requirements for budgetary frameworks of the member states was passed ${ }^{4}$ (hereinafter the directive) in 2011. In accordance with the definition adopted in the directive, budgetary frameworks are meant as a set of arrangements, procedures, rules and institutions that underlie the conduct of efficient budgetary policies of general government. The directive systematises the scope of frameworks as follows: systems of accounting and statistics, forecasting procedures, numeric fiscal rules, budgetary procedures, medium-term budgetary frameworks that extend the horizon for fiscal policy-making, transparency of the processes and relationships between public authorities across sub-sectors.

However, the wording of either convergence programmes or stability programmes prepared by European countries does not confirm that the quality and measurability of the effects of public spending is a significant area of interest for fiscal authorities. In this wording, it is hard to find any information indicating the use of efficiency data as part of the measures aimed at decreasing fiscal imbalance.

A certain lack of consistency can be observed also in the approach to the use of quality information in the OECD. In the OECD report published as of the end of 2012, which assesses the condition of member states' public finance, a classification of respective countries is presented in terms of the need for fiscal consolidation (from the highest to the lowest, or lack thereof) (OECD, Restoring Public Finances, 2012 Update, OECD Publishing, Paris, 2012, p. 24). However, the assessment does not take into account (or, at least, it is not included in the publication) the qualitative approach to the allocation of public funds as an element of the consolidation process used.

The times of crisis are the best test of efficiency and utility of economic policy instruments. From this perspective, initial observations indicate that the set of measures referred to as PB have not really proved useful in the period in which the pressure on public spending efficiency should be extremely high. Objective circumstances force respective governments to limit the overall level of public spending so that this should be done in such a way as to preserve the funding for priority public tasks and to decrease expenditure, mainly where it brings the weakest effect. Robinson (2015), upon reviewing changes in OECD countries' public finance systems, which were enforced by deteriorating budgetary balance at the time of financial crisis, observed that both the objectives and instruments of fiscal adjustment utterly overlook the instruments of PB. The desirable structure and prioritisation of spending is not indicated, and there is no analysis of the consequences that a reduction of expenditure will have in respective areas of the state activity. Objectives are set in purely quantitative terms, at an aggregate level, that is, what is formulated is the target level of fiscal balance (the amount of public deficit and debt), as well as the overall level of spending and the necessary scale of cuts (Cangiano, Lazare \& Curristine, 2013, p. 49). Instruments to achieve macroeconomic objectives include mechanisms such as imposed spending limits or incorporating the so-called fiscal rules in the legal system (e.g. quantitative public debt limits).

\section{Results of quantitative research}

The relatively small sample (19 countries $\left.^{5}\right)$ and the short timeline, that is, the years 2008-2016, give rise to reasonable concerns as to the actual significance of the quantitative correlations revealed; however, some irregularities can be noticed, and it is worth either trying to verify them in the future or taking account of other research methods, which we try to do later in this article (Tables 1 and 2 in Addendum).

The correlation is calculated without taking Ireland into account because the country's GDP dynamics are very high (in 2015, GDP grew by more than 25\%), which reflects, however, a high difference between GDP and GNP (Gross National Product), rather than the real output growth. This results from the fact that Ireland, being a tax haven, is a place of formal registration of many companies. Those 'abnormal' results as to GDP, and the small sample, cause the entire correlation to be greatly distorted.

As can be seen, these simple quantitative correlations allow a couple of conclusions:

4 Council Directive 2011/85/EU of 8 November 2011 on requirements for budgetary frameworks of the member states, OJ L 306. 23.11.2011, p. 41.

5 Baltic states, that is, Lithuania, Latvia and Estonia, were not yet eurozone members in 2009, but their respective currencies were pegged to the euro, which, from the perspective of monetary requirements, is nearly tantamount to membership of the monetary union. 
Tab. 1: Fiscal adjustment, social and economic indicators and the level of advancement of PB* implementation in eurozone countries.

\begin{tabular}{|c|c|c|c|c|c|c|c|}
\hline GEO/TIME & $\begin{array}{l}\text { Primary fiscal } \\
\text { balance in } \\
2009 \text { (\% of } \\
\text { GDP) }\end{array}$ & $\begin{array}{l}\text { Primary } \\
\text { fiscal } \\
\text { balance } \\
2016 \text { (\% of } \\
\text { GDP) }\end{array}$ & $\begin{array}{l}\text { Primary } \\
\text { balance - } \\
\text { change in } \\
\text { percentage } \\
\text { points }\end{array}$ & $\begin{array}{l}\text { Average GDP } \\
\text { dynamics in } \\
2009-2016\end{array}$ & $\begin{array}{l}\text { Change in Gini } \\
\text { coefficient } \\
2009-2015 \text { in } \\
\text { points }\end{array}$ & $\begin{array}{l}\text { Change in } \\
\text { poverty level } \\
\text { in percentage } \\
\text { points 2009- } \\
2015\end{array}$ & $\begin{array}{l}\text { Advancement } \\
\text { in PB }\end{array}$ \\
\hline Belgium & -1.6 & 0.3 & 1.9 & 0.8 & -0.2 & 0.9 & 0 \\
\hline Germany & -0.6 & 2.2 & 2.8 & 1.1 & 1.0 & 0.0 & 0 \\
\hline Greece & -10.1 & 3.9 & 14 & -3.7 & 1.1 & 8.1 & 0 \\
\hline Cyprus & -3.1 & 3.0 & 6.1 & -0.8 & 4.1 & 5.4 & 0 \\
\hline Latvia & -7.6 & 1.1 & 8.7 & 0.2 & -2.1 & -7.0 & 0 \\
\hline Lithuania & -7.9 & 1.7 & 9.6 & 1.0 & 2.0 & -0.3 & 0 \\
\hline Luxembourg & -0.3 & 1.9 & 2.2 & 2.6 & -0.7 & 0.7 & 0 \\
\hline Malta & 0.0 & 3.2 & 3.2 & 3.8 & 0.7 & 2.1 & 0 \\
\hline Portugal & -6.8 & 2.2 & 9 & -0.5 & -1.4 & 1.7 & 0 \\
\hline Finland & -1.2 & -0.8 & 0.4 & -0.5 & -0.7 & -0.1 & 1 \\
\hline Spain & -9.3 & -1.7 & 7.6 & -0.2 & 1.7 & 3.9 & 2 \\
\hline France & -4.8 & -1.5 & 3.3 & 0.6 & -0.7 & -0.8 & 2 \\
\hline Netherlands & -3.4 & 1.5 & 4.9 & 0.5 & -0.5 & 1.3 & 2 \\
\hline Ireland & -11.8 & 1.7 & 13.5 & 4.7 & 1.0 & 0.3 & 3 \\
\hline Italy & -0.9 & 1.6 & 2.5 & -0.7 & 0.6 & 3.8 & 3 \\
\hline Austria & -2.2 & 0.5 & 2.7 & 0.6 & -0.3 & -0.8 & 3 \\
\hline Slovenia & -4.6 & 1.4 & 6 & -0.2 & 1.8 & 2.1 & 3 \\
\hline Slovakia & -6.4 & 0.0 & 6.4 & 1.9 & -1.1 & -1.2 & 3 \\
\hline Estonia & -2.0 & 0.4 & 2.4 & 0.8 & 3.4 & 0.8 & 3 \\
\hline
\end{tabular}

* Construction of the index described in page 5.

Source: Eurostat.

Tab. 2: Correlations for groups of countries with different levels of advancement of PB implementation

\begin{tabular}{|c|c|c|c|c|c|}
\hline Correlation and PB advancement & PBo & $\mathrm{PB1}^{*}$ & PB2 & $\mathrm{PB}_{3}$ & $\mathrm{~PB}_{3}$ without Ireland \\
\hline Fiscal adjustment vs. GDP dynamics & -0.78231 & & -0.98805 & 0.909127 & 0.375668 \\
\hline Fiscal adjustment vs. Gini dynamics & 0.049315 & & 0.954803 & -0.119 & \\
\hline Fiscal adjustment vs. change in poverty & 0.241961 & & 0.996365 & -0.24216 & \\
\hline
\end{tabular}

Source: Own calculation based on Eurostat data.

"There is only one country with the index of ' 1 ', so there is no point in calculating a correlation here. 
Fig. 1: Number of countries with fiscal adjustment greater than $0.5 \%$ of GDP in a single year.

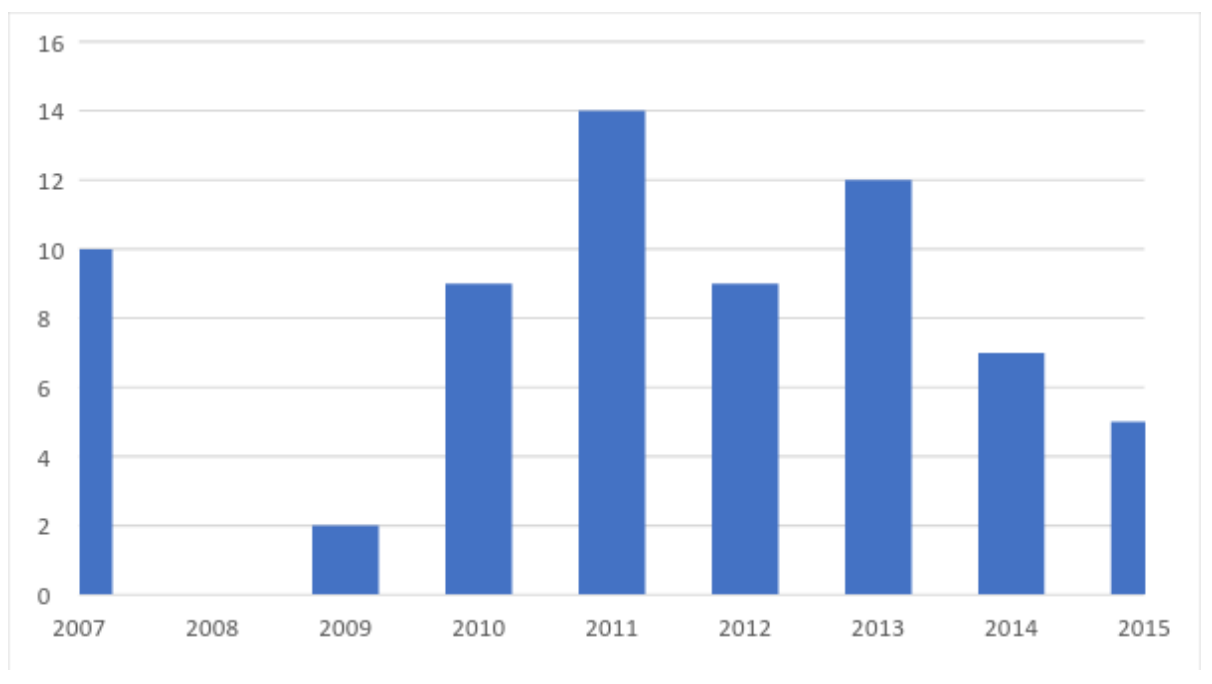

Source: Author's calculations based on Eurostat data

- Countries where PB is relatively widely applied in public finance management achieve much better results than do economies where PB instruments are not used.

- This can be seen most of all in the impact of fiscal adjustment on GDP dynamics: countries that are advanced in PB implementation achieve a positive correlation between the scale of adjustment and GDP dynamics, that is, fiscal imbalance reduction leads to faster growth in those countries (even when Ireland is excluded from the sample), contrary to those countries with a lesser or zero use of $\mathrm{PB}$, where the correlation is strong and negative, that is, the fiscal adjustment has strong recessionary effects.

- The situation is similar for the effect of fiscal adjustment on income inequality indicators and the scale of poverty: countries that apply advanced PB methods can combine budgetary imbalance reduction with an improvement in social indicators, whilst the opposite is true in the other cases, that is, an improved condition of public finance comes at the cost of an increase in poverty and income inequalities.

- The above comments require thorough reflection, because a clear lack of cohesion can be seen in the presented calculation results, namely, correlations for the group of countries with an index of 2 as regards the level of advancement of PB implementation. This group of countries gets much 'worse' results (high correlations that go in an undesirable direction) than do the group of economies that use no PB instruments. However, it needs to be emphasised that this group is exceptionally small (only three countries), so the quantitative correlations may be misleading and may result from the specificity of those countries.

More sophisticated methods of quantitative analysis were used to capture other links. The goal of the study is to check the extent to which fiscal adjustment is related to active management of the public spending structure, that is, the extent to which a change of fiscal imbalance is related to the dynamics of respective spending categories.

A decision was made to use models for panel data. Panel data contain variables observed in at least two dimensions, for example, spatial and temporal (many objects observed in many periods). Panel data can be analysed using classical least-squares method estimation, fixed effects modelling and random effects modelling (Gruszecki, 2002, p. 47). The importance of panel models is emphasised by Griliches and Intriligator (2007). The wide use of panel models in econometric analyses is also presented by Baltagi (2003). To achieve that goal, analyses were conducted on panel data (balanced panel), with model panels built using the generalised maximum likelihood estimation method, a fixed effects panel model and a random effect panel model (it follows from the experience to date that this model is not suitable for the data used, but there has been no attempt to use it). 
First and foremost, an attempt was made to identify the factors/types of expenditure that have an impact on the scale of fiscal adjustment in the countries studied. This was a point of departure for further analysis regarding the impact of performance budget on fiscal adjustment because, as mentioned earlier in this article, the process of understanding and implementing this tool varies (sometimes it is partial and only refers to a specific group of expenditures listed in COFOG database).

The point of departure for the analysis conducted was the scale of fiscal adjustment in the period analysed, which is presented by the data provided in Figure 1. In the model being built, this was an exogenous variable.

The endogenous variables were the 171 variables $^{6}$ picked based on the substantive knowledge (set of potential endogenous variables) and then selected using Hellwig's method (Welfe 2013). When building the panel model, it was expected that random components for each of the countries in the coming years would be correlated, and, consequently, it would not be possible to treat them as separate observations of basic models for non-panel data. Therefore, the basic model specification must be extended to include a part that measures unobservable country-specific heterogeneity. The general form of effects models (Greene, 2002) is

$y_{i t}^{*}=x^{\prime}{ }_{i t} \beta+v_{i t}+u_{i}, i=1, \ldots, n, t=1, \ldots, T_{i}$

$y_{i t}=1$, if $y_{i t}^{*}>0.0$ in p.p. (percenatge points)

where $u_{\mathrm{i}}$ is the unobservable country-specific heterogeneity.

A special case of the above model, used to analyse data relating to factors affecting the fiscal adjustment, is the fixed effects logit model:

$y_{i t}^{*}=\alpha_{i} d_{i t}+x^{\prime}{ }_{i t} \beta+\varepsilon_{i t}, i=1, \ldots, n, t=1, \ldots, T_{i}$

$y_{i t}=1$, if $y_{i t}^{*}>0.0$ in p.p.

where dit= 1 for a given country $i$, otherwise 0 .

Hence, the log likelihood function for this model has the following form:

$\ln L=\sum_{i=1}^{n} \sum_{t=1}^{T_{i}} \ln P\left(y_{i t} \mid \alpha_{i}+x^{\prime}{ }_{i t} \beta\right)$

where $P$ is the probability of the observed result.

In the model defined in this way, the study was conducted on a sample of 171 observations: data for 19 eurozone countries from 2007 to 2015 for the variables adopted, as presented in Table 3.

As a result of the model defined in this way, the results obtained (full data are provided in Addenda 1 and 2) indicate that only two variables are of significance at 0.05 : share of defence expenditure and housing and community amenities' expenditure. These two variables have a negative impact on the probability of fiscal adjustment - improvement in the original budget balance by at least 0.5 percentage points. At 0.1 , another significant variable is that illustrating the share of public order and safety expenditure. If the share of this expenditure in total government spending is above the sample average, the probability of fiscal adjustment increases, meaning that active policy has been implemented only in the case of these spending categories.

The results achieved also indicate that the factors that drive the level of fiscal adjustment in the countries analysed can be divided into stimulants and de-stimulants, which helps determine the strength and direction of the impact of specified variables on the fiscal situation. This allows streamlining the finance management process and focusing on measures that help improve the financial situation of the countries analysed as regards fiscal adjustment. A higher share of safety expenditure can be classified as one of the success determinants for fiscal adjustment in the countries analysed. The increase in those variables has a positive effect on the probability of exceeding 0.5 percentage points of fiscal adjustment or on the probability of fiscal adjustment. In the process of managing public funds and shaping fiscal adjustment instruments on the spending side, special attention should be given to this group of spending categories in the eurozone countries analysed.

6 Database consists of statistics on structure of public expenditures and macroeconomic variables in the given countries in the given years; normality of the data distribution has not been tested. 
Tab. 3. Variables used in the model.

\begin{tabular}{lll}
\hline Variable & Name & Coding \\
\hline Fiscal adjustment & F_ADJ & $\begin{array}{l}\text { Binary variable that takes the value of } 1 \text { if general government primary net } \\
\text { lending/borrowing (\% GDP) has increased by at least o.5 percentage point }\end{array}$ \\
\hline Government spending & EXP_P & $\begin{array}{l}\text { Normalised continuous variable, government expenditure improvement/ } \\
\text { deterioration (\% GDP), in percentage points }\end{array}$ \\
\hline General public services & PUB_SER & Normalised continuous variable, percentage share of total government spending \\
\hline Defence & DEFENCE & Normalised continuous variable, percentage share of total government spending \\
\hline Public order and safety & SAFETY & Normalised continuous variable, percentage share of total government spending \\
\hline Economic affairs & ECON_AF & Normalised continuous variable, percentage share of total government spending \\
\hline Environment protection & ENVIRON & Normalised continuous variable, percentage share of total government spending \\
\hline Housing and community amenities & HOUSING & Normalised continuous variable, percentage share of total government spending \\
\hline Health & HEALTH & Normalised continuous variable, percentage share of total government spending \\
\hline Recreation, culture and religion & CULTURE & Normalised continuous variable, percentage share of total government spending \\
\hline Education & EDUC & Normalised continuous variable, percentage share of total government spending \\
\hline Social protection & SOCIAL & Normalised continuous variable, percentage share of total government spending \\
\hline
\end{tabular}

Source: Own compilation.

If we collate the results obtained in this way with the information on performance budget, especially in the areas of expenditure where this tool was applied, it is hard to clearly establish whether the hypothesis put forward at the beginning of this article is correct. The model studies conducted allow us neither to confirm nor to disprove it unambiguously. However, they prove the hypothesis that fiscal adjustment cannot be modelled: it depends on political decisions taken in a given country. The two expenditure groups identified, defence and housing and community amenities, are fixed and cannot be an element of the fiscal consolidation process in the short run.

\section{Conclusions}

Economic and social costs of fiscal adjustment are quite big in some eurozone countries, as can be judged according to the scale of GDP decline and huge increases in unemployment rate experienced by, for example, Greece and Spain. Despite having the same macroeconomic conditions (central bank interest rate and exchange rate), there are big differences between eurozone economies in the social cost of adjustment, which can be measured as growth in income inequalities and the size of poverty level. The obvious reason for these differences should be the quality of public finance management - countries that are more advanced in implementing modern tools of public management should be able to minimise the social cost budget of rebalancing. Some basic quantitative exercise seems to support this statement: economies that are the most advanced in using PB tools show much better results in the case of income distribution and poverty level. A very short time period and a limited sample size do not allow us to draw general conclusion on the relationship between the use of PB tools and the ability of the public sector to minimise cost of public expenditures cuts. A more sophisticated research method based on a bigger data pool does not support the statement that the use of specified goals and measured outcomes of public policies, which are the most important tools of $\mathrm{PB}$, determines conducting active policy by making big changes in the public expenditures structures what would suggest that priorities of public policy have been chosen. There is no significant statistical proof that countries advanced in implementing PB tools conduct more active policy mean as a change in 
the expenditure structure. A common approach to public expenditure management during a period of fiscal adjustment is rather 'to cut across the border', just to fulfil goals of fiscal strategy based on general measures such as public debt, budget deficit or total level of public spending. To sum up, the PB method of managing public finance has obvious advantages, so it should be especially useful in periods of fiscal adjustment. The results of our preliminary research show that real policy is conducted in a much different way.

\section{REFERENCES}

Greene, W. H., Econometric Analysis (seventh ed.). Upper Saddle River, NJ: Prentice Hall, New York University 2012.

Alesina A., Perotti R., Tavares J., The Political Economy of Fiscal Adjustments, Brookings Papers on Economic Activity, 1:1998.

Cangiano M., Lazare M.; Curristine T., Public Financial Management and Its Emerging Architecture, IMF, Washington 2013.

Dell'Erba, Mattina, Roitman., Pressure or Prudence? Tales of Market Pressure and Fiscal Adjustment, IMF Working Paper WP/13/170, Washington 2013.

EisenkopfG., Negative Weights for Performance Measures, International Public Management Journal, 12:3, 332-344, 2009

European Commission, European Union Public Finance: New book edition released, Brussels 2015.

IMF, Fiscal Monitor, Washington 2012 and 2013.

Kelly, J., Rubin, M., Budget and Accounting Reforms. In Ferlie, E., Lynn, L. and Pollitt, C. (Eds.), The Oxford Handbook of Public Management, (pp. 563-590). 2005 New York.

Maarten de Jong, Iris van Beek and Rense Posthumus, Introducing accountable budgeting: lessons from a decade of performance-based budgeting in the Netherlands, OECD Journal on Budgeting Volume $2012 / 3$.
Nuti M., Polityka oszczędnościowa a rozwój, w: Kołodko G.W., (red.) Zarządzanie i polityka gospodarcza dla rozwoju, Poltext, Warszawa 2014 .

Perotti R., The "Austerity Myth": Gain Without Pain?, BIS Working Paper 362,2011

Robinson M., BUDGET REFORM BEFORE AND AFTER THE GLOBAL FINANCIAL CRISIS 36th ANNUAL OECD SENIOR BUDGET OFFICIALS MEETING, Paris 2015.

Tanzi V., Realistic Recovery Why Keynesian Solutions Will Not Work, Politeia 2012

Utz H., Better Performance with PB? Analyzing Cases of Success and Failure in Public Administrations, International Public Management Journal, 13:4, 408-428, 2010

Weber A., Stock-Flow Adjustments and Fiscal Transparency: A CrossCountry Comparison, IMF Working Paper, WP/12/39, 2012.

Welfe W., Ekonometria. Metody i ich zastosowanie, PWE, Warsaw 2014 


\section{Addendum}

Tab. 1: First estimate of the model

\begin{tabular}{lllllll}
\hline Variable & Factor & Standard error & Statistics & p-Value & 95\% confidence interval & Variable \\
\hline EXP_P & -.65163 & .60126 & -1.08 & .2785 & -1.83007 & .52682 \\
\hline PUB_SER & -.04402 & .79740 & -.06 & .9560 & -1.60690 & 1.51886 \\
\hline DEFENCE & $-1.81173^{* * *}$ & .66220 & -2.74 & .0062 & -3.10963 & -.51383 \\
\hline SAFETY & 1.05193 & .72048 & 1.46 & .1443 & -.36018 & 2.46405 \\
\hline ECON_AF & -.32410 & .44170 & -.73 & .4631 & -1.18982 & .54162 \\
\hline ENVIRON & -.62397 & .47758 & -1.31 & .1914 & -1.56001 & .31207 \\
\hline HOUSING & $-1.57105^{* *}$ & .63935 & -2.46 & .0140 & -2.82415 & -.31795 \\
\hline HEALTH & .77236 & .87788 & .88 & .3790 & -.94825 & 2.49298 \\
\hline CULTURE & -.60845 & .70308 & -.87 & .3868 & -1.98645 & .76956 \\
\hline EDUC & -.29718 & 1.08384 & -.27 & .7839 & -2.42146 & 1.82710 \\
\hline
\end{tabular}

Source: Own compilation

Tab. 2: Final model results

\begin{tabular}{lllllll}
\hline Variable & Factor & Standard error & Statistics & p-Value & 95\% confidence interval & Variable \\
\hline DEFENCE & $\mathbf{- 1 . 1 7 6 5 4 * *}$ & $\mathbf{. 5 3 9 4 5}$ & $\mathbf{- 2 . 1 8}$ & $\mathbf{. 0 2 9 2}$ & $\mathbf{- 2 . 2 3 3 8 4}$ & -.11925 \\
\hline SAFETY & $1.06680^{*}$ & .55212 & 1.93 & .0533 & -.01534 & 2.14894 \\
\hline HOUSING & $-1.66726 * * *$ & .57675 & -2.89 & .0038 & -2.79768 & -.53684 \\
\hline
\end{tabular}

Source: Own compilation 